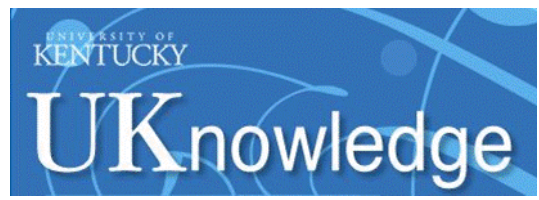

University of Kentucky

UKnowledge

Chemical and Materials Engineering Faculty

Publications

Chemical and Materials Engineering

$12-12-2015$

\title{
High Capacity Silicon Electrodes with Nafion as Binders for Lithium-Ion Batteries
}

Jiagang Xu

University of Kentucky, jg.xu@uky.edu

Qinglin Zhang

University of Kentucky, qinglinzhang@uky.edu

Yang-Tse Cheng

University of Kentucky, yang.t.cheng@uky.edu

Follow this and additional works at: https://uknowledge.uky.edu/cme_facpub

Part of the Chemical Engineering Commons, and the Materials Science and Engineering Commons Right click to open a feedback form in a new tab to let us know how this document benefits you.

\section{Repository Citation}

Xu, Jiagang; Zhang, Qinglin; and Cheng, Yang-Tse, "High Capacity Silicon Electrodes with Nafion as Binders for Lithium-Ion Batteries" (2015). Chemical and Materials Engineering Faculty Publications. 48. https://uknowledge.uky.edu/cme_facpub/48

This Article is brought to you for free and open access by the Chemical and Materials Engineering at UKnowledge. It has been accepted for inclusion in Chemical and Materials Engineering Faculty Publications by an authorized administrator of UKnowledge. For more information, please contact UKnowledge@lsv.uky.edu. 


\section{High Capacity Silicon Electrodes with Nafion as Binders for Lithium-Ion Batteries}

\section{Digital Object Identifier (DOI)}

https://doi.org/10.1149/2.0261603jes

\section{Notes/Citation Information}

Published in Journal of The Electrochemical Society, v. 163, issue 3, p. A401-A405.

(c) The Author(s) 2015. Published by ECS.

This is an open access article distributed under the terms of the Creative Commons Attribution 4.0 License (CC BY, http://creativecommons.org/licenses/by/4.0/), which permits unrestricted reuse of the work in any medium, provided the original work is properly cited. 


\title{
High Capacity Silicon Electrodes with Nafion as Binders for Lithium-Ion Batteries
}

\author{
Jiagang $\mathrm{Xu},{ }^{\mathrm{Z}}$ Qinglin Zhang, and Yang-Tse Cheng \\ Department of Chemical and Materials Engineering, University of Kentucky, Lexington, Kentucky 40506, USA
}

\begin{abstract}
Silicon is capable of delivering a high theoretical specific capacity of $3579 \mathrm{mAh} \mathrm{g}^{-1}$ which is about 10 times higher than that of the state-of-the-art graphite based negative electrodes for lithium-ion batteries. However, the poor cycle life of silicon electrodes, caused by the large volumetric strain during cycling, limits the commercialization of silicon electrodes. As one of the essential components, the polymeric binder is critical to the performance and durability of lithium-ion batteries as it keeps the integrity of electrodes, maintains conductive path and must be stable in the electrolyte. In this work, we demonstrate that electrodes consisting of silicon nanoparticles mixed with commercially available Nafion and ion-exchanged Nafion can maintain a high specific capacity over 2000 $\mathrm{mAh} \mathrm{g}^{-1}$ cycled between $1.0 \mathrm{~V}$ and $0.01 \mathrm{~V}$. For comparison, the capacity of electrodes made of the same silicon nanoparticles mixed with a traditional binder, polyvinylidene fluoride (PVDF), fades rapidly. In addition, stable cycling at $1 \mathrm{C}$ rate for more than 500 cycles is achieved by limiting the lithiation capacity to $1200 \mathrm{mAh} \mathrm{g}^{-1}$.

(C) The Author(s) 2015. Published by ECS. This is an open access article distributed under the terms of the Creative Commons Attribution 4.0 License (CC BY, http://creativecommons.org/licenses/by/4.0/), which permits unrestricted reuse of the work in any medium, provided the original work is properly cited. [DOI: 10.1149/2.0261603jes] All rights reserved.
\end{abstract}

Manuscript submitted October 27, 2015; revised manuscript received December 2, 2015. Published December 12, 2015. This was Paper 446 presented at the Chicago, Illinois, Meeting of the Society, May 24-28, 2015.

There is an intense effort worldwide to develop new electrode materials for lithium-ion batteries (LIBs) to satisfy future high power and energy density applications. Silicon can provide theoretical capacity up to $3579 \mathrm{mAh} \mathrm{g}^{-1}$ (based on $\mathrm{Li}_{15} \mathrm{Si}_{4}$ ), which is about ten times higher than that of graphite electrode. ${ }^{1}$ Resulting from large volume changes as lithium goes into and out of silicon, cracking and pulverization of Si electrodes can cause the loss of electrical contact and new solid electrolyte interphase (SEI) formation on exposed surface, leading to rapid capacity fade. Novel binders and nanostructured silicon are two general approaches to improve the durability and performance of silicon electrodes.

For commercial LIBs, electrodes are composed of three essential components, which are active material, conductive additive and binder. The fundamental role of binder is to keep the electrode mechanically intact and adhered well to the current collector. Other ideal characteristics of binders include electrochemical stability over wide potential range, high melting point, low swelling rate in nonaqueous electrolyte, high lithium ionic conductivity, high electrical conductivity, capability to sustain volume change of active material particles, and good manufacturability. ${ }^{2-4}$ Today, polyvinylidene fluoride (PVDF, monomer $-\mathrm{CH}_{2}-\mathrm{CF}_{2}$ ) and styrene butadiene rubber (SBR) are commonly used as binders for graphite anodes, and PVDF and polytetrafluoroethylene (PTFE, monomer $-\mathrm{CF}_{2}-\mathrm{CF}_{2}-$ ) can be used as binders for cathodes. $^{2}$

PVDF is known to perform poorly for high energy density electrode materials, such as silicon, because it fails to accommodate the large volume change during lithiation and delithiation. ${ }^{5,6}$ Presently, there is much interest in developing effective binders for siliconbased electrodes. Crosslinked elastomeric polymer (PVDF + tetrafluoroethylene + propylene) was shown to maintain good capacity retention for amorphous $\mathrm{Si}-\mathrm{Sn}$ electrodes in spite of the $125 \%$ volume change. ${ }^{7}$ Carboxymethyl cellulose (CMC) and SBR were widely studied to improve the cycle life of silicon-based electrodes. ${ }^{8-13}$ Polyfluorene based conductive polymer without adding conductive carbon black was shown to accommodate the volume change of silicon, and high capacity and long term cycling were achieved simultaneously. ${ }^{14}$ Magasinski and coworkers first reported the use of polyacrylic acid (PAA) as a binder, which shows low swellability in carbonate electrolyte and high elastic modulus. The high concentration of carboxylic groups in PAA was attributed to the good electrochemical performance. ${ }^{6}$ Similar to CMC and PAA, some polysaccharides extracted from natural products were demonstrated as binders for silicon nanoparticles with stable cycling behavior. ${ }^{15,16}$
Lithium ion-exchanged Nafion has been reported as a binder to improve the cycling performance of micro-sized crystalline silicon powders (particle size, $44 \mu \mathrm{m}$ ). ${ }^{17}$ Sulfur-carbon electrode coated with Nafion was also demonstrated to improve the electrochemical bahavior of lithium sulfur batteries. ${ }^{18}$ Moreover, Nafion has been used in large scale applications as membranes in fuel cells because of its high protonic conductivity due to the sulfonic acid group $\left(-\mathrm{SO}_{3} \mathrm{H}^{+}\right)$. After ion exchange in $\mathrm{LiOH}$ solution, Nafion becomes $\mathrm{Li}^{+}$conductive, which therefore has been considered as a candidate material for separator or electrolyte in lithium batteries. ${ }^{4,19-21}$

Inspired by previous findings, we, in this work, investigated the electrochemical performance of silicon nanoparticles mixed with either Nafion or PVDF as a binder. Ion-exchanged Nafion was also studied as a binder to compare with pure Nafion binder by replacing protons with $\mathrm{Li}^{+}$. Unlike the rapid capacity fade of silicon electrodes with PVDF as a binder, we found that Nafion and ion-exchanged Nafion were both able to deliver specific capacity of silicon electrode more than $2000 \mathrm{mAh} \mathrm{g}^{-1}$ after 100 cycles with a high Coulombic efficiency. The specific capacity of silicon nanoparticles secured by Nation binders is comparable to that of nanostructured silicon electrodes, e.g., nanowires. ${ }^{3,15,22}$ In addition, both rate capability test and long term cycling test show ion-exchanged Nafion can yield better performance of silicon electrode compared with Nafion.

\section{Experimental}

Electrodes are composed of $50 \mathrm{wt} \%$ silicon powder (size 30-50 $\mathrm{nm}$, Nanostructured \& Amorphous Materials), $25 \mathrm{wt} \%$ conductive carbon black (Super P C65, TIMCAL) and 25 wt\% binder. Binders used in our work include PVDF (Alfa Aesar), Nafion solution (D-520, Alfa Aesar) and ion-exchanged Nafion. The ion-exchanged Nafion solution was prepared in a customized titration set-up operated at room temperature. A $0.01 \mathrm{M} \mathrm{LiOH}$ (Sigma-Aldrich) aqueous solution was used as the titrant. The density of the Nafion solution is $0.93 \mathrm{~g} \mathrm{~mL}^{-1}$, and the ion exchange capacity is typically 1.03 to $1.12 \mathrm{meq} \mathrm{g}^{-1}$. For $1 \mathrm{~mL}$ of Nafion solution, it takes about $5 \mathrm{~mL}$ of $\mathrm{LiOH}$ aqueous solution to complete the ion exchange process. The N-Methyl-2-pyrrolidone (NMP, 99.5\%, Alfa Aesar) solvent was used to dissolve PVDF. Uniform slurries were obtained by mixing powders in a small sample vial immersed in an ultrasonic bath for 30 minutes. Finally, the slurry was casted onto a battery grade $\mathrm{Cu}$ foil (thickness, $12 \mu \mathrm{m}$ ) by using a $127 \mu \mathrm{m}$ doctor blade.

Electrodes with diameter of $10 \mathrm{~mm}$ were punched from dried uniform laminates, and then were further dried at $130^{\circ} \mathrm{C}$ for 12 hours in a vacuum oven. The silicon and lithium $(0.38 \mathrm{~mm}$ thick, SigmaAldrich) disks were assembled as the positive and negative electrodes 


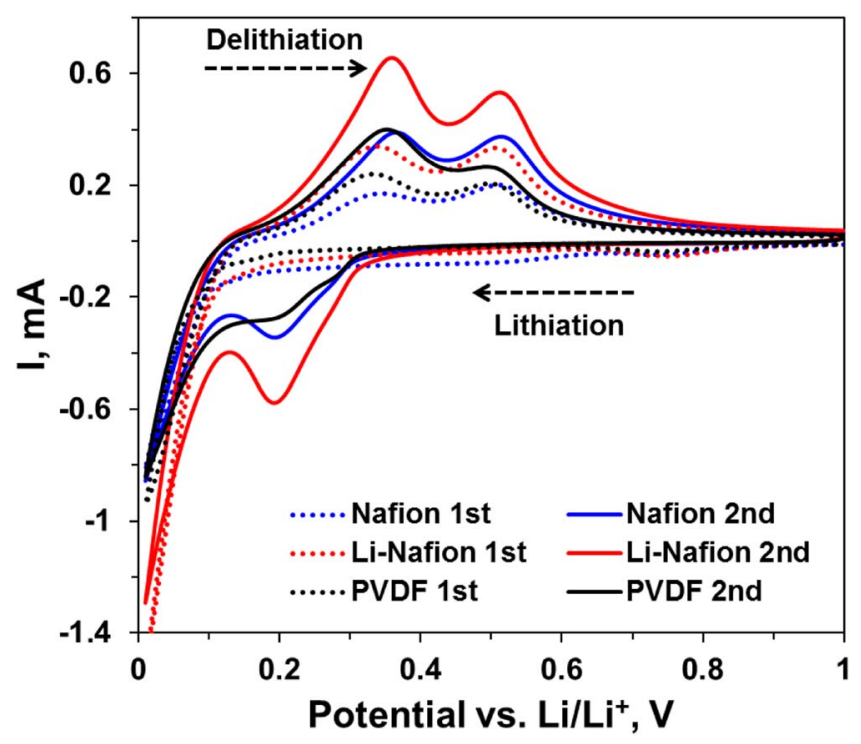

Figure 1. Cyclic voltammograms of silicon electrodes with different binders. The voltage limits are $1.0 \mathrm{~V}$ and $0.01 \mathrm{~V}$, and the potential scanning rate is $0.1 \mathrm{mV} \mathrm{s}^{-1}$.

in CR2025 type coin cells in an argon-filled glove box $(<0.1 \mathrm{ppm}$ of both oxygen and moisture, MBRAUN). One piece of microporous polypropylene film, Celgard 3501, was used as the separator in each cell. The electrolyte was $1 \mathrm{M} \mathrm{LiPF}_{6}$ salt in a mixture of ethylene car- bonate and diethyl carbonate (EC:DEC $=1: 1$ vol $\%$, BASF). For comparison, the same electrolyte was prepared with an additive of $10 \mathrm{wt} \%$ fluoroethylene carbonate (FEC, BASF). Unless otherwise mentioned in this paper, testing was carried out in coin cells without the FEC additive in the electrolyte. Cycling tests (discharge/charge curves, C-rate is expressed as $\mathrm{C} / \mathrm{R}$, for example, $\mathrm{C} / 10$ means 10 hours are required to completely discharge/charge) and rate capability tests were conducted under galvanostatic mode using two Bio-Logic potentiostats (MPG-2 and VMP-3) at room temperature. The theoretical capacity of $3600 \mathrm{mAh} \mathrm{g}^{-1}$ for silicon was used to calculate discharge/charge currents. Cyclic voltammograms (CV) were taken using Bio-Logic potentiostats (MPG-2 and VMP-3) between $1.0 \mathrm{~V}$ and $0.01 \mathrm{~V}$ with a potential scanning rate of $0.1 \mathrm{mV} \mathrm{s}^{-1}$.

X-ray photoelectron spectroscopy (XPS, K-Alpha system, Thermo Scientific) was used to determine the chemical composition of pristine electrode and SEI layer on electrode surface after 10 cycles at the C/10 rate. For XPS measurements, post-cycled electrodes were obtained by disassembling the coin cells inside an argon-filled glove box and then washed thoroughly with the dimethyl carbonate (DMC, BASF) solvent and dried inside the argon-filled glove box. They were then transferred to the XPS analysis chamber without exposing to air using a Vacuum Transfer Module (Thermo Scientific).

\section{Results and Discussion}

The electrochemical characteristics of silicon electrodes with different binders were first examined by cyclic voltammetry between 1.0 $\mathrm{V}$ and $0.01 \mathrm{~V}$ at a relatively slow potential scanning rate of $0.1 \mathrm{mV}$ $\mathrm{s}^{-1}$. The cyclic voltammograms for the first two cycles are shown in Fig. 1. In the 1st cycle, no obvious peaks were present during

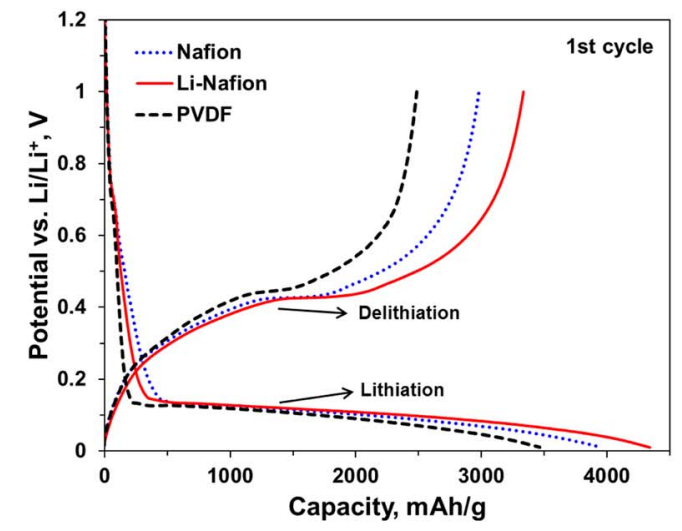

(a)

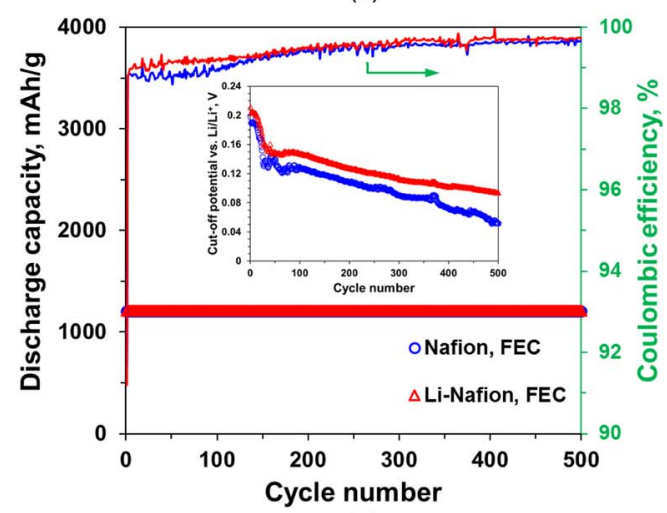

(c)

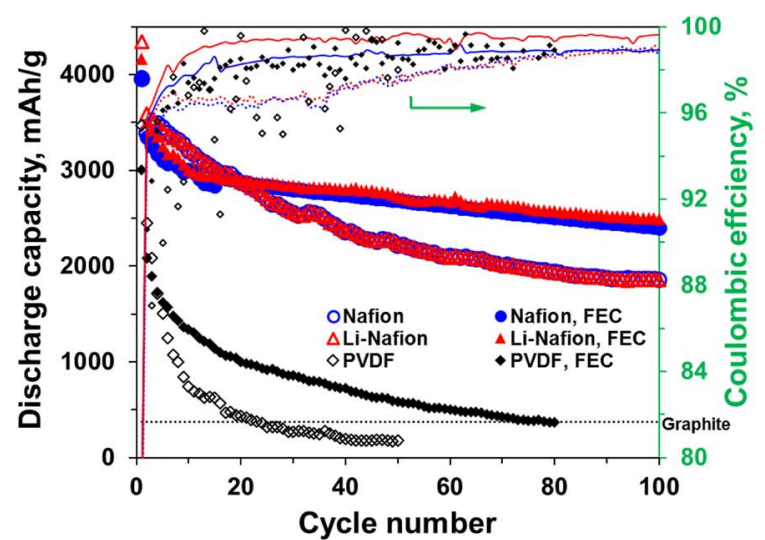

(b)

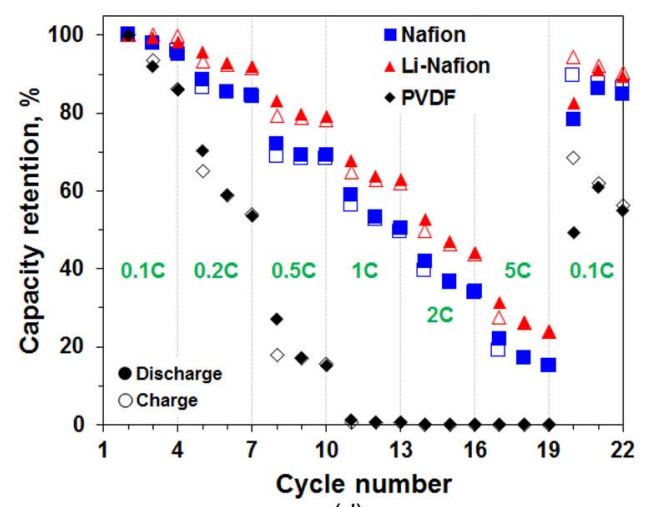

(d)

Figure 2. Electrochemical characteristics of silicon electrodes containing different binders, and the testing potential window was from $0.01 \mathrm{~V}$ to $1.0 \mathrm{~V}$ vs. Li/Li $\mathrm{i}^{+}$, (a) Initial discharge/charge voltage profile cycled at $\mathrm{C} / 10$. (b) Discharge capacity and Coulombic efficiency vs. cycle number tested at $\mathrm{C} / 10$, curves with filled markers and solid lines are for electrodes with FEC in electrolyte and curves with empty markers and dotted lines are for electrodes without FEC in electrolyte. (c) Discharge capacity and lithiation cut-off potential vs. cycle number for electrodes with Nafion as binders and the presence of FEC in the electrolyte tested at $1 \mathrm{C}$ with a capacity limit of $1200 \mathrm{mAh} \mathrm{g}^{-1}$. (d) Normalized discharge/charge capacity retention at different current densities, $1 \mathrm{C}=3600 \mathrm{~mA} \mathrm{~g}-1$, filled marker indicates discharge process and empty marker indicates charge process. 
lithiation as the crystalline silicon was transformed to an amorphous $\mathrm{Li}-\mathrm{Si}$ alloy. Because the potential reached $10 \mathrm{mV}$, the high lithium concentration $\mathrm{Li}_{15} \mathrm{Si}_{4}$ phase with a theoretical capacity of $3579 \mathrm{mAh}$ $\mathrm{g}^{-1}$ was formed. ${ }^{1,23}$ The cross over between lithiation and delithiation curve in the 1st cycle around $0.1 \mathrm{~V}$ could be attributed to continuous SEI formation. ${ }^{24}$ During delithiation, two types of amorphous silicon phases $\left(\mathrm{a}-\mathrm{Li}_{\mathrm{x}} \mathrm{Si}\right)$ formed as indicated by the respective peaks around $0.3 \mathrm{~V}$ and $0.5 \mathrm{~V}$, though the detailed mechanism of forming these two amorphous phases was unknown. ${ }^{15,23-25}$ In the 2 nd cycle, the peaks around $0.2 \mathrm{~V}$ and $0.01 \mathrm{~V}$ were attributed to lithium alloying with amorphous silicon, and the delithiation peaks were around $0.3 \mathrm{~V}$ and $0.5 \mathrm{~V}$. For all the electrodes, delithiation peaks shifted to the right as the electrodes were cycled. This increase in the overpotential was due to continuous SEI formation on the electrode surface, causing impedance rise.

In order to know more about the electrochemical performance of silicon electrode mixed with different binders, these electrodes were cycled between $1.0 \mathrm{~V}$ and $0.01 \mathrm{~V}$ under constant current at room temperature. The amount of silicon was about $0.4 \mathrm{mg} \mathrm{cm}^{-2}$ for all sample electrodes. The initial discharge/charge voltage vs. capacity curve is shown in Fig. 2a. For crystalline silicon electrodes, amorphization always happens during the first cycle as indicated by the plateau in the discharge curve as seen in Fig. 2a. These voltage profiles are very similar to those reported in the literature. ${ }^{3,6,15}$
The specific capacity and Coulombic efficiency vs. cycle number curves for electrodes with different binders and electrolytes are shown in Fig. 2b. The capacity of silicon electrode with PVDF binder degraded drastically after the 1 st cycle. In contrast, the capacity retention of silicon electrodes using pure or ion-exchanged Nafion as binders is much improved. In the absence of FEC in the electrolyte, the initial capacity based on pure silicon mass was 3466, 3956 and 4342 $\mathrm{mAh} \mathrm{g}^{-1}$, for electrodes containing PVDF, Nafion and ion-exchanged Nafion, respectively. Since the specific capacity was calculated using the measured silicon mass in each electrode, the value of specific capacity may have error depending on the accuracy of silicon mass measurement. This may explain why the specific capacity of 4342 $\mathrm{mAh} \mathrm{g}^{-1}$ is larger than the theoretical capacity of $4200 \mathrm{mAh} \mathrm{g}^{-1}$ for the most lithium saturated phase $\mathrm{Li}_{22} \mathrm{Si}_{5}$.

The Coulombic efficiency is an important indicator for the cycling stability of electrodes. From Fig. 2b, the Coulombic efficiency in the 1st cycle was $72 \%, 75 \%$ and $77 \%$ for silicon electrodes with PVDF, Nafion and ion-exchanged Nafion as binders, respectively. The initial low Coulombic efficiency was due to the irreversible $\mathrm{Li}$ loss caused by the formation of SEI. An increase in the Coulombic efficiency after the 1st cycle suggests that most SEI formed during the first discharge process. As a result of large volume changes upon cycling, the loss of active silicon particles and a continuous growth of SEI on freshly exposed silicon surface were believed to

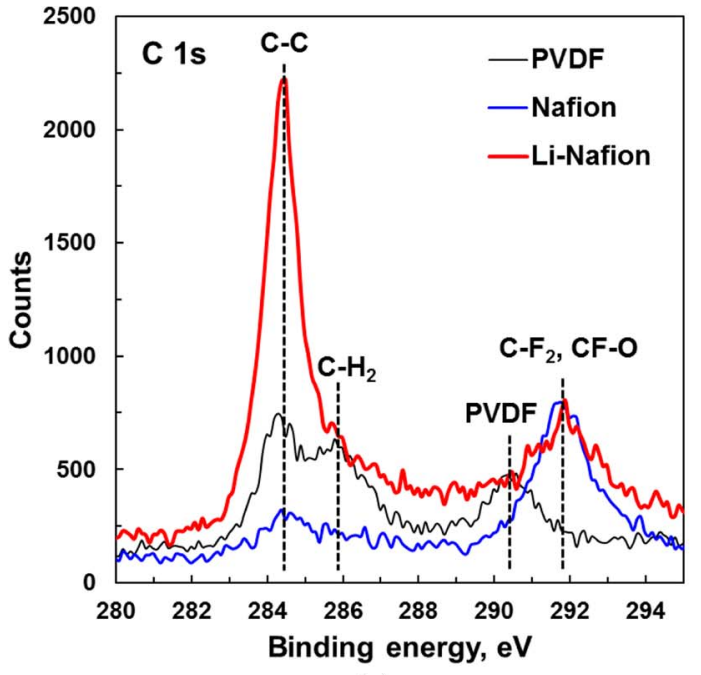

(a)

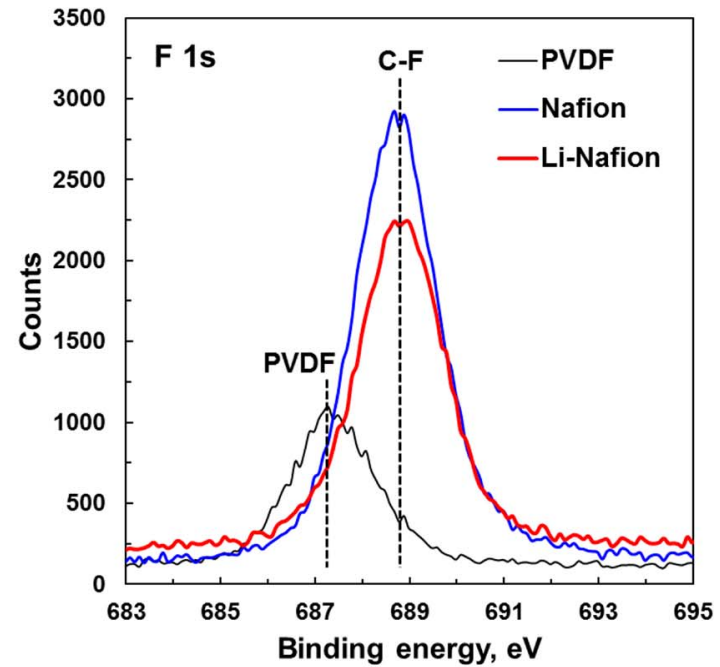

(b)

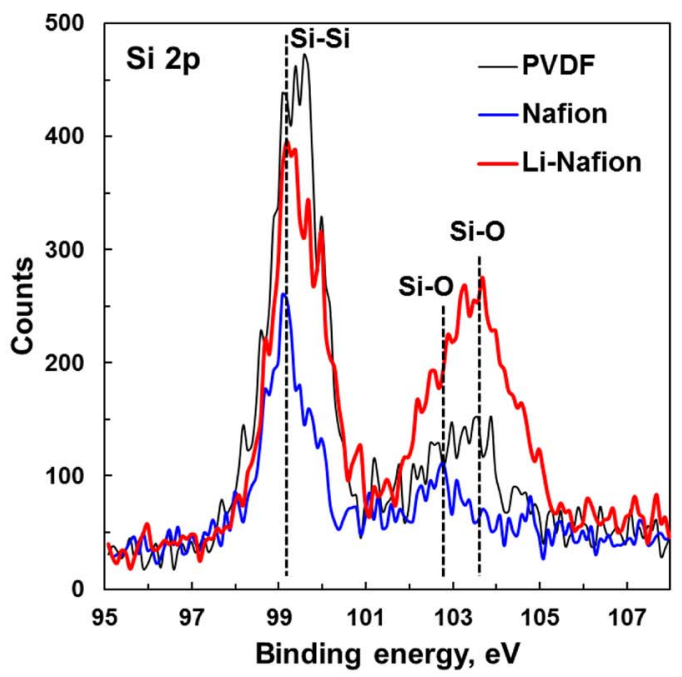

(c)

Figure 3. XPS spectra of pristine electrodes containing different binders, (a) C 1s peaks. (b) F $1 \mathrm{~s}$ peaks. (c) Si $2 p$ peaks. 
be the cause of low Coulombic efficiency and irreversible capacity loss.

FEC was reported to yield stable cycling of silicon electrodes by forming stable and unique SEI film protecting silicon against oxidation and electrolyte from decomposition. ${ }^{26,27}$ In Fig. 2b, higher capacity retention (with filled markers) and higher Coulombic efficiency (in solid lines) of silicon electrodes with Nafion binders were obtained using the electrolyte with the FEC additive. Moreover, Fig. 2c shows stable cycling of silicon nanoparticles mixed with Nafion binders for 500 cycles at a rate of $1 \mathrm{C}$ with a lithiation capacity limit of $1200 \mathrm{mAh} \mathrm{g}^{-1}$. The morphology and continuous formation of SEI during long term cycling for silicon electrode mixed with Nafion and ion-exchanged Nafion could be different and this would lead to the difference of both impedance rise of the cell and state of charge of active silicon nanoparticles. Indeed, lithiation cutoff potential vs. cycle number curve in Fig. 2c indicates that silicon/ion-exchanged Nafion cell behaves better due to the higher cutoff potentials, suggesting the lower impedance and longer cycle life of the cell. The cyclic test results based on Nafion and ion-exchanged Nafion binders are quite comparable with that of sodium alginate and are better than that of CMC, which are widely studied binders in recent years. ${ }^{15}$

Fig. 2d compares the discharge/charge capacity retention at different current densities for silicon electrodes mixed with different binders at room temperature normalized based on the data from the 2nd cycle. The theoretical capacity $3600 \mathrm{mAh} \mathrm{g}^{-1}$ for silicon was used to calculate discharge/charge currents, thus current density for $1 \mathrm{C}$ was $3600 \mathrm{~mA} \mathrm{~g}^{-1}$ for all the electrodes. Since the performance of $\mathrm{Si} / \mathrm{PVDF}$ was very poor at $\mathrm{C} / 10$, its capacity retention was, unsurprisingly, close to zero at $1 \mathrm{C}, 2 \mathrm{C}$ and $5 \mathrm{C}$. We suggest that PVDF around silicon particles cannot effectively guarantee fast lithium ion transport and thus lithiation and delithiation were incomplete at high current densities. On the other hand, silicon electrodes with Nafion and ion-exchanged Nafion as binders were still cycleable at $1 \mathrm{C}, 2 \mathrm{C}$, and 5C. Furthermore, the ion-exchanged Nafion yielded better rate performance compared with pure Nafion as seen in Fig. 2d which is likely due to its superior capability to provide lithium transport paths to silicon nanoparticles.

XPS measurements were carried out to study the chemical composition of the surface of the electrodes before and after electrochemical cycling tests. Fig. 3 shows C 1s, F 1s and Si 2p spectra for the fresh electrodes containing different binders, which were always stored inside an argon-filled glove box after fabrication. In Fig. 3a, the first $\mathrm{C} 1 \mathrm{~s}$ peak at $284.5 \mathrm{eV}$ is attributed to carbon black and C-C bonds in PVDF and Nafion binders. The second peak around $286 \mathrm{eV}$ and the third peak at $290.4 \mathrm{eV}$ are identified as $\mathrm{C}-\mathrm{H}_{2}$ bonds and $\mathrm{C}-\mathrm{F}_{2}$ bonds in PVDF, respectively. The last peak around $291.8 \mathrm{eV}$ corresponds to $\mathrm{CF}_{2} / \mathrm{CF}$ groups in Nafion and ion-exchanged Nafion. ${ }^{28}$ From Fig. 3b, the first F 1 s peak at $687.4 \mathrm{eV}$ is assigned to $\mathrm{CF}$ groups in PVDF and the second peak at $688.8 \mathrm{eV}$ is assigned to $\mathrm{CF}$ groups in Nafion and ion-exchanged Nafion. ${ }^{28}$ In Fig. $3 c$, the first broad peak around

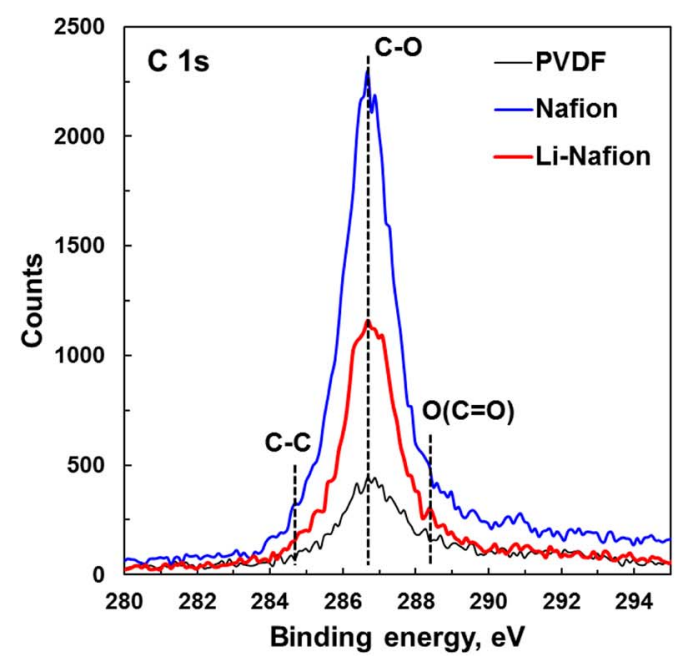

(a)

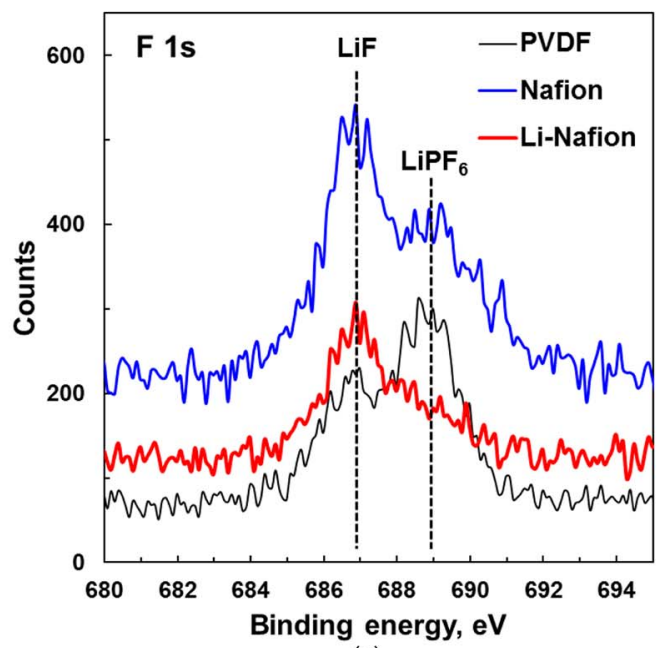

(c)

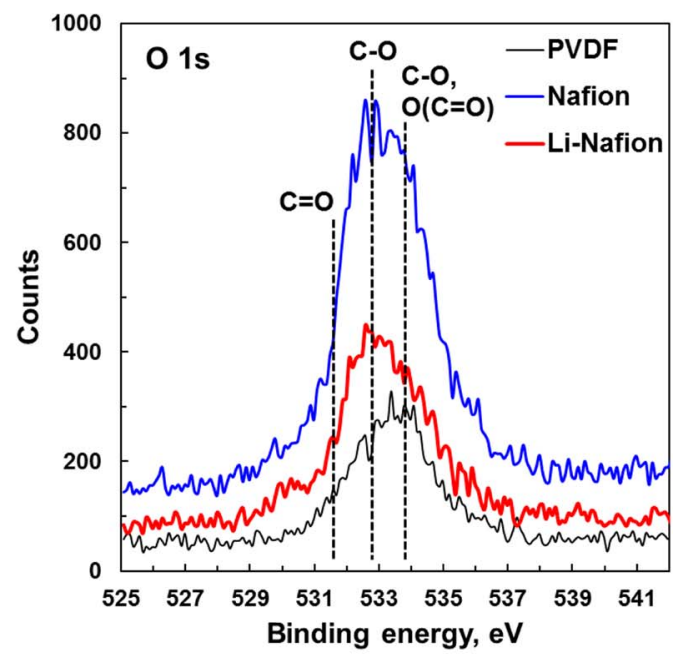

(b)

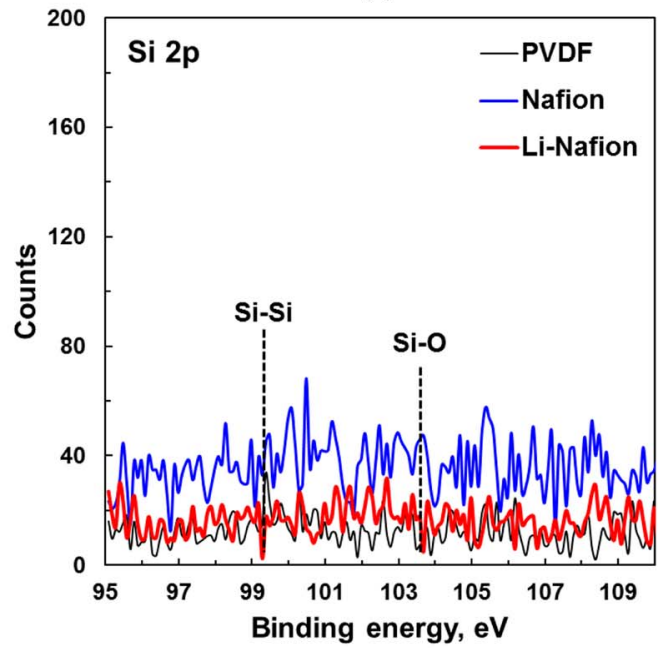

(d)

Figure 4. XPS spectra of electrodes containing different binders after 10 discharge/charge cycles at the $\mathrm{C} / 10$ rate, electrodes were holding at $1.0 \mathrm{~V}$ for 2 hours after 10th charge, (a) $\mathrm{C}$ 1s peaks. (b) O 1s peaks. (c) F 1s peaks. (d) Si 2p peaks. 
$100 \mathrm{eV}$ indicates the existence of silicon, and the second broad peak around $103.5 \mathrm{eV}$ indicates the existence of silicon oxides on silicon surface. $^{24}$

XPS spectra (C 1s, O 1s, F 1s and Si 2p) for electrodes containing different binders after 10 discharge/charge cycles between $1.0 \mathrm{~V}$ and $0.01 \mathrm{~V}$ at $\mathrm{C} / 10$ are presented in Fig. 4. No FEC was added when testing these electrodes. By the end of the 10th charging process, all the electrodes were held at $1.0 \mathrm{~V}$ for 2 hours in order to complete delithiation. In Fig. 4a, the C-C peak, which is usually associated with carbon black and alkane species or surface hydrocarbon contamination, is absent for Nafion and ion-exchanged Nafion and it is also invisible for PVDF. Kovalenko and coworkers reported a similar result but this phenomenon is still very different from other reports. ${ }^{15,24,29}$ The peak around $286.8 \mathrm{eV}$ can be attributed to $\mathrm{C}-\mathrm{O}$ bonds in carbonaceous solvent reduction products (for example, ethers ROLi, esters RCOOLi and alkyl carbonate solutions $\mathrm{ROCO}_{2} \mathrm{Li}$ ) and the peak at $288.5 \mathrm{eV}$ can be attributed to $\mathrm{O}-\mathrm{C}=\mathrm{O}$ bond in alkyl carbonate solutions. ${ }^{29,30}$ Moreover, the peak at $290 \mathrm{eV}$ for $\mathrm{Li}_{2} \mathrm{CO}_{3}$ formation is not seen in the cases of these three binders. This is possibly due to the amount of formed $\mathrm{Li}_{2} \mathrm{CO}_{3}$ after 10 cycles is insufficient for XPS detection or $\mathrm{Li}_{2} \mathrm{CO}_{3}$ is very close to the silicon particle surface and is covered by other organic SEI components. A single broad $\mathrm{O} 1 \mathrm{~s}$ peak centered at around $533 \mathrm{eV}$ is observed in Fig. 4b, which is likely caused by species containing $\mathrm{C}=\mathrm{O}$ bonds at around $531.5 \mathrm{eV}$ and $\mathrm{C}-\mathrm{O}$ bonds at $533-534 \mathrm{eV}$ and $\mathrm{O}-\mathrm{C}=\mathrm{O}$ bonds at around $534 \mathrm{eV}^{24}$ In Fig. $4 \mathrm{c}$, a dominant peak at around $687 \mathrm{eV}$ indicates the formation of $\mathrm{LiF}$ and the peak at around $689 \mathrm{eV}$ indicates the presence of $\mathrm{LiPF}_{6}$ residue and its decomposed products $\mathrm{Li}_{x} \mathrm{PF}_{\mathrm{y}} \mathrm{O}_{\mathrm{z}}$. Additionally, based on Fig. 4c, it seems that PVDF is favorable for formation of inorganic $\mathrm{Li}_{\mathrm{x}} \mathrm{PF}_{\mathrm{y}} \mathrm{O}_{\mathrm{z}}$ and unfavorable for $\mathrm{LiF}$ formation. Unlike fresh electrodes, no useful information can be extracted from the Si $2 p$ spectra shown in Fig. 4d because silicon particles are completely covered by SEI. The LiF has been widely accepted as a beneficial SEI component for improved cycling behavior, especially when FEC is used as the electrolyte additive. ${ }^{31-33}$ By comparing with our FEC free case, we suggest that both Nafion and ion-exchanged Nafion have the capability of transporting lithium ions to silicon nanoparticles and thus maintaining relatively stable cycling performance as seen in Fig. 2 b.

\section{Conclusions}

Ionic conducting polymers Nafion and ion-exchanged Nafion were shown to be promising binders for silicon electrodes in lithium-ion batteries. For comparison, PVDF was shown to be unsuited for silicon electrodes because of the poor cycling behavior. For silicon nanoparticles, Nafion with or without ion exchange resulted in long cycling durability with a high capacity of more than $2000 \mathrm{mAh} \mathrm{g}^{-1}$ for 100 cycles at the $\mathrm{C} / 10$ current rate. It is further confirmed that the better performance of silicon electrodes was achieved by adding a small amount of FEC to the electrolyte. Nafion binders were believed to be capable of transporting lithium ions and forming ionic conductive films between the liquid electrolyte and silicon particles. This work not only demonstrates Nafion as promising binders for silicon electrodes but also inspires more efforts to better understand binding mechanisms.

\section{Acknowledgments}

Financial support from National Science Foundation (Award number: 1355438, Powering the Kentucky Bioeconomy for a Sustainable Future) is gratefully acknowledged.

\section{References}

1. M. N. Obrovac and L. Christensen, Electrochem Solid St, 7, A93 (2004).

2. M. Yoshio, R. J. Brodd, and A. Kozawa, Lithium-Ion Batteries: Science and Technologies, Springer-Verlag New York, (2009).

3. M. Y. Wu, X. C. Xiao, N. Vukmirovic, S. D. Xun, P. K. Das, X. Y. Song, P. Olalde-Velasco, D. D. Wang, A. Z. Weber, L. W. Wang, V. S. Battaglia, W. L. Yang, and G. Liu, J Am Chem Soc, 135, 12048 (2013).

4. Z. J. Cai, Y. B. Liu, S. S. Liu, L. Li, and Y. M. Zhang, Energ Environ Sci, 5, 5690 (2012).

5. D. Mazouzi, Z. Karkar, C. R. Hernandez, P. J. Manero, D. Guyomard, L. Roue, and B. Lestriez, J Power Sources, 280, 533 (2015).

6. A. Magasinski, B. Zdyrko, I. Kovalenko, B. Hertzberg, R. Burtovyy, C. F. Huebner, T. F. Fuller, I. Luzinov, and G. Yushin, Acs Appl Mater Inter, 2, 3004 (2010).

7. Z. H. Chen, L. Christensen, and J. R. Dahn, Electrochem Commun, 5, 919 (2003).

8. W. R. Liu, M. H. Yang, H. C. Wu, S. M. Chiao, and N. L. Wu, Electrochem Solid St, 8, A100 (2005)

9. H. Buqa, M. Holzapfel, F. Krumeich, C. Veit, and P. Novak, J Power Sources, 161, 617 (2006).

10. J. Li, R. B. Lewis, and J. R. Dahn, Electrochem Solid St, 10, A17 (2007).

11. B. Lestrie, S. Bahri, I. Sandu, L. Roue, and D. Guyomard, Electrochem Commun, 9 , 2801 (2007).

12. N. S. Hochgatterer, M. R. Schweiger, S. Koller, P. R. Raimann, T. Wohrle, C. Wurm, and M. Winter, Electrochem Solid St, 11, A76 (2008).

13. D. Mazouzi, B. Lestriez, L. Roue, and D. Guyomard, Electrochem Solid St, 12, A215 (2009).

14. G. Liu, S. D. Xun, N. Vukmirovic, X. Y. Song, P. Olalde-Velasco, H. H. Zheng, V. S. Battaglia, L. W. Wang, and W. L. Yang, Adv Mater, 23, 4679 (2011).

15. I. Kovalenko, B. Zdyrko, A. Magasinski, B. Hertzberg, Z. Milicev, R. Burtovyy, I. Luzinov, and G. Yushin, Science, 334, 75 (2011).

16. M. Murase, N. Yabuuchi, Z. J. Han, J. Y. Son, Y. T. Cui, H. Oji, and S. Komaba, Chemsuschem, 5, 2307 (2012).

17. R. R. Garsuch, D. B. Le, A. Garsuch, J. Li, S. Wang, A. Farooq, and J. R. Dahn, $J$ Electrochem Soc, 155, A721 (2008).

18. Q. W. Tang, Z. Q. Shan, L. Wang, X. Qin, K. L. Zhu, J. H. Tian, and X. S. Liu, $J$ Power Sources, 246, 253 (2014).

19. Y. B. Liu, Z. J. Cai, L. Tan, and L. Li, Energ Environ Sci, 5, 9007 (2012).

20. Z. Q. Jin, K. Xie, X. B. Hong, Z. Q. Hu, and X. Liu, J Power Sources, 218, 163 (2012).

21. H. Y. Liang, X. P. Qiu, S. C. Zhang, W. T. Zhu, and L. Q. Chen, J Appl Electrochem, 34, 1211 (2004)

22. A. M. Chockla, T. D. Bogart, C. M. Hessel, K. C. Klavetter, C. B. Mullins, and B. A. Korgel, J Phys Chem C, 116, 18079 (2012)

23. M. N. Obrovac and L. J. Krause, J Electrochem Soc, 154, A103 (2007).

24. K. W. Schroder, H. Celio, L. J. Webb, and K. J. Stevenson, J Phys Chem C, 116, 19737 (2012)

25. T. L. Kulova, A. M. Skundin, Y. V. Pleskov, E. I. Terukov, and O. I. Kon'kov, J Electroanal Chem, 600, 217 (2007)

26. H. Nakai, T. Kubota, A. Kita, and A. Kawashima, J Electrochem Soc, 158, A798 (2011).

27. N. S. Choi, K. H. Yew, K. Y. Lee, M. Sung, H. Kim, and S. S. Kim, J Power Sources, 161, 1254 (2006).

28. K. Feng, B. B. Tang, and P. Y. Wu, J Mater Chem A, 3, 12609 (2015)

29. B. Philippe, R. Dedryvere, J. Allouche, F. Lindgren, M. Gorgoi, H. Rensmo, D. Gonbeau, and K. Edstrom, Chem Mater, 24, 1107 (2012).

30. D. Aurbach, J Power Sources, 89, 206 (2000).

31. V. Etacheri, O. Haik, Y. Goffer, G. A. Roberts, I. C. Stefan, R. Fasching, and D. Aurbach, Langmuir, 28, 965 (2012).

32. Q. L. Zhang, X. C. Xiao, W. D. Zhou, Y. T. Cheng, and M. W. Verbrugge, Adv Energy Mater, 5 (2015)

33. J. Pan, Y. T. Cheng, and Y. Qi, Phys Rev B, 91 (2015). 